\title{
Computational Model for Prediction of the Occurrence of Steam Pops during Irrigated Radiofrequency Catheter Ablation
}

\author{
Ana González-Suárez ${ }^{1,2}$, Enrique Berjano², Jose M Guerra ${ }^{3}$, Luca Gerardo-Giorda ${ }^{1}$ \\ ${ }^{1}$ BCAM-Basque Center for Applied Mathematics, Bilbao, Basque Country, Spain \\ ${ }^{2}$ Biomedical Synergy, Department of Electronic Engineering, Universitat Politècnica de València, \\ València, Spain \\ ${ }^{3}$ Department of Cardiology, Hospital de la Santa Creu i Sant Pau, Barcelona, Spain
}

\begin{abstract}
Radiofrequency catheter ablation (RFCA) is a curative treatment for cardiac arrhythmias. Although globally a pretty safe procedure, it may present some risk. Steam pop is a serious complication that can occur during RFCA with irrigated electrodes. Pops are caused by tissue overheating above $89^{\circ} \mathrm{C}$, and may cause explosive rupture of myocardial wall. Today, it is still very complicated to predict the occurrence and location of steam pops into the tissue during RFCA. Our aim was to use a computational model to address these issues considering two irrigated catheter tip designs and different power settings. The model has been validated against existing experimental results. Computational results show no evidence of significant differences in the incidence of steam pops between the two catheter designs. Steam pops appears at powers higher than $30 \mathrm{~W}$ at approximately $2 \mathrm{~mm}$ depth under the electrode tip. Overall, the computational findings were in close agreement with previous experimental results, which suggests that the proposed model could be useful to predict the occurrence of steam pops in different clinical situations.
\end{abstract}

\section{Introduction}

Radiofrequency catheter ablation (RFCA) is a wellestablished, minimally invasive medical procedure intended to destroy thermally cardiac arrhythmias. Irreversible destruction is produced as soon as the tissue temperature exceeds $50^{\circ} \mathrm{C}$ during several seconds. Unfortunately, under some common conditions in the clinical practice, the tissue underneath the electrode experiences a fast overheating (above $100^{\circ} \mathrm{C}$ ), and water molecules produce steam inside the tissue. When the trapped steam pressure is extreme, an explosive rupture occurs [1]. This phenomenon is known as popping and could be potentially hazardous, especially when ablation is conducted on a thin layer of myocardium as in the case of atrium wall. To date, different techniques have been explored to predict the imminent occurrence of steam pops [1-2]. However, it is difficult to assess which factors could conduct to the steam pops formation in clinical practice. Computational modeling could be a powerful tool to determine these factors and to guide the medical doctors in the prevention of steam pops formation. In this paper we aim to study the factors involving in pops occurrence and their location in the cardiac tissue simulating different clinical situations. We base the present study on a previously developed and validated computational model of an open-irrigated electrode for endocardial RFCA which was presented at CinC 2015[3].

\section{Methods}

\subsection{Computational modeling}

The three-dimensional model consists of a fragment of cardiac tissue, a volume of blood and an open-irrigated electrode in different positions with respect to the cardiac tissue. The electrode is endowed with a sensor embedded in its tip for temperature monitoring. We consider, besides the open-irrigated electrode (8Fr diameter and 3.5 $\mathrm{mm}$ length) with 6- holes presented in [3], a multi-holes electrode with 56- holes distributed around its entire distal tip [4] (see Figure 1 for the perpendicular positioning). These designs of electrodes represent two available commercial catheters for RFCA: ThermoCool ${ }^{\circledR}$ (6-holes) and ThermoCool $\mathrm{SF}^{\circledR}$ (56-holes), both from Biosense Webster (Diamond Bar, CA, USA). The tiny holes on the tip allow the saline cooling solution to continuously flow into the cardiac chamber. The flowing saline mixes with the circulating blood without forming a film around the electrode. The effect of saline flow is modeled as an inlet boundary condition into the blood region, set at the zone where the holes are located (see violet surface in Figure 1) [4].

The thermal and electrical properties of the model 
elements are obtained from [4]. The initial model temperature is $37^{\circ} \mathrm{C}$, except in the electrode tip which is $22^{\circ} \mathrm{C}$, imposed as a consequence of the saline irrigation. The electrical $(\sigma)$ and thermal conductivity $(k)$ of cardiac tissue are temperature-dependent and are defined by piecewise functions as described in [4].

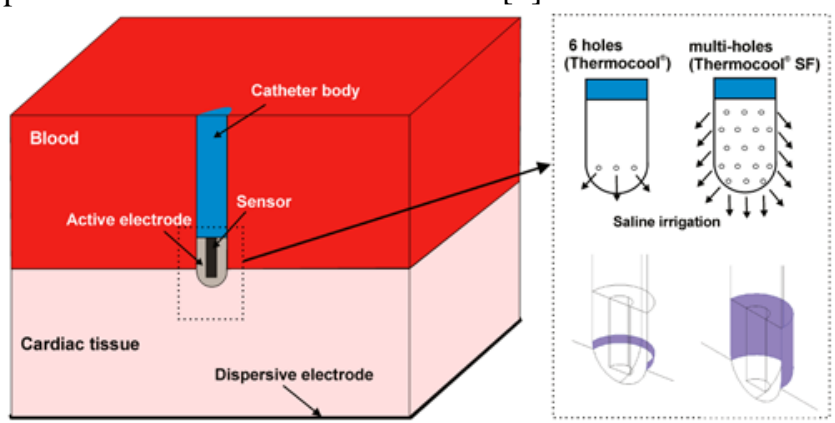

Figure 1. Geometry of the computational model built.

Electrical, thermal and velocity boundary conditions are applied to the model. We considered constant power ablation mode, which is the standard modality for openirrigated electrodes in RFCA. We implemented a proportional-integral control algorithm using MATLAB (MathWorks, Natick, MA, USA) and the applied voltage was modulated to maintain the delivering power within $3 \%$ of the target. Therefore, a voltage boundary condition is hence applied at the active electrode surface. On all the outer surfaces of the model, except the bottom surface, a null electrical flux is imposed. The voltage on the bottom surface is set to $0 \mathrm{~V}$ to model the dispersive electrode. For the thermal boundary conditions, a null thermal flux is used on the symmetry plane and a constant temperature of $37^{\circ} \mathrm{C}$ is fixed on the outer model surfaces. For the velocity boundary conditions, an inlet velocity boundary condition is applied on the left surface of the fluid volume to impose a blood flow velocity of $0.1 \mathrm{~m} \mathrm{~s}^{-1}$ [5]. An outlet boundary condition of zero pressure is fixed on the right surface of the fluid volume. The saline irrigation flow is taken into account by an inlet velocity condition into the blood region. A no slip condition is applied on the upper surfaces of the fluid volume, at the symmetry plane and at the tissue-blood and electrode-blood interfaces.

The model is based on a coupled electric-thermal-flow problem, which is solved numerically using the Finite Element Method (FEM) with COMSOL Multiphysics software (COMSOL, Burlington, MA, USA). The governing equation for the thermal problem is the Bioheat Equation, modified by the enthalpy method [4] that includes the phase change to model tissue vaporization:

$\frac{\partial(\rho h)}{\partial t}=\nabla \cdot(k \nabla T)+q-\rho c \boldsymbol{u} \cdot \nabla T$

where $\rho$ is density $\left(\mathrm{kg} \mathrm{m}^{-3}\right), h$ enthalpy, $t$ time (s), $k$ thermal conductivity $\left(\mathrm{W} \mathrm{m}^{-1} \mathrm{~K}^{-1}\right), T$ temperature $\left({ }^{\circ} \mathrm{C}\right)$, and $q$ the heat source caused by RF power $\left(\mathrm{W} \mathrm{m}^{-3}\right)$. In a more general form, model (1) could also include terms accounting for heat loss caused by blood perfusion and for metabolic heat generation. However, since it has been demonstrated that the blood flow away from the coronary arteries does not have significant influence on the temperature distribution during RFCA, and the metabolic heat generation is negligible in comparison to the other terms [6], such quantities are not considered here. The advection term in Equation (1) represents the heat loss due to blood flow. The velocity field $\boldsymbol{u}(\mathrm{m} / \mathrm{s})$ is governed by the incompressible Navier-Stokes Equations [7].

At RF frequencies $(\approx 500 \mathrm{kHz})$ and over the distance of interest, the biological medium can be considered almost totally resistive, and a quasi-static approach can therefore be used to solve the electrical problem, which allows calculating the value of $q$ [6].

\subsection{Modeling of steam pop occurrence}

We considered that a pop occurred for a volumetric tissue temperature higher than $89.3^{\circ} \mathrm{C}$. We also checked the rate of tissue temperature change at the time of pop occurrence, since it has been demonstrated that a rate higher than $1.5^{\circ} \mathrm{C} / \mathrm{s}$ is an independent predictor of pop formation [2].

We first assessed the accuracy of the computational model by comparing the computational results with available data from experiments $[2,8]$. These simulations were conducted using the same conditions as in the experiments [2]: 6-holes electrode in perpendicular position over the tissue, saline irrigation flow rate of 30 $\mathrm{mL} / \mathrm{min}$, power settings from 20 to $50 \mathrm{~W}$ and ablation time determined by the occurrence of a steam pop.

Second, we used the model to study the effect of the electrode design on the pop occurrence. In particular, we compared the 6-holes vs. 56-holes electrode, considering different positions of the electrode respect to the tissue surface. We assessed the time at which steam pop occurs and its location in the tissue.

\section{Results}

\subsection{Validation of the computer model}

We compared the time at which pops occurred using the same powers settings as in the experiments [2] for the 6-holes electrode (see Table 1). In the experiments, steam pops occurred at $29.2 \pm 15.7 \mathrm{~s}$ for a power delivered of $32.7 \pm 8.8 \mathrm{~W}$. The model is in close agreement with the experiments, since we obtained steam pops for powers $\geq 35 \mathrm{~W}$, specifically with power pops at $28 \mathrm{~s}$. As in the experiments, the volumetric temperature of the tissue change was higher than $1.5^{\circ} \mathrm{C} / \mathrm{s}$ when pops occurred at the tissue, specifically we obtained $1.9,3.1$ and $5.5^{\circ} \mathrm{C} / \mathrm{s}$ with 35,40 and $50 \mathrm{~W}$ at the instant of pop occurrence. 
Table 1. Computational validation with previous experimental studies using the 6-holes electrode (data from [2,8])

\begin{tabular}{|c|c|c|c|c|c|c|c|}
\hline \multirow[b]{2}{*}{$\begin{array}{l}\text { Power } \\
\text { (W) }\end{array}$} & \multicolumn{4}{|c|}{ Computer results } & \multicolumn{3}{|c|}{ Experimental results } \\
\hline & $\begin{array}{l}\text { Time } \\
\text { pop (s) }\end{array}$ & $\begin{array}{r}\text { Depth } \\
\text { pop (mm) }\end{array}$ & $\begin{array}{l}\text { Electrode } \\
\text { temp. }\left({ }^{\circ} \mathrm{C}\right)\end{array}$ & $\begin{array}{r}\text { Temp. } \\
\text { rate }\left({ }^{\circ} \mathrm{C} / \mathrm{s}\right)\end{array}$ & Time pop (s) & $\begin{array}{l}\text { Electrode } \\
\text { temp. }\left({ }^{\circ} \mathrm{C}\right)\end{array}$ & $\begin{array}{l}\text { Temp. } \\
\text { rate }\left({ }^{\circ} \mathrm{C} / \mathrm{s}\right)\end{array}$ \\
\hline 20 & $\mathrm{~N}$ & $\mathrm{~N}$ & 38.89 & 0.52 & \multirow{2}{*}{$\mathrm{N}$} & $37 \pm 3$ & $1.5 \pm 1.9$ \\
\hline 30 & $\mathrm{~N}$ & $\mathrm{~N}$ & 40.22 & 0.85 & & - & $1.5 \pm 1.9$ \\
\hline 35 & 28 & 2.17 & 40.40 & 1.89 & \multirow{3}{*}{$\begin{array}{c}29.2 \pm 15.7 \\
(32.7 \pm 8.8 \mathrm{~W})\end{array}$} & $40 \pm 4$ & $4.6 \pm 3.3$ \\
\hline 40 & 17 & 2.07 & 40.52 & 3.08 & & - & $4.6 \pm 3.3$ \\
\hline 50 & 10 & 1.99 & 40.96 & 5.46 & & $42 \pm 3$ & $4.6 \pm 3.3$ \\
\hline
\end{tabular}

We also measured the maximum temperature at the catheter tip and we obtained similar temperatures as in the experiments for the 6-holes electrode [8]. In particular, the maximum temperature at the electrode tip in the model was $38.9,40.4$ and $41^{\circ} \mathrm{C}$ for 20,35 and $50 \mathrm{~W}$, whereas in the experiments was $37 \pm 3,40 \pm 4$ and $42 \pm$ $3^{\circ} \mathrm{C}$ for the same powers settings.

\subsection{Prediction of steam pops}

Figure 2 depicts the time at which steam pops occurred and their location in the cardiac tissue, i.e. the depth under the electrode tip at which the steam pop is located, for the 6-holes and multi-holes electrodes considering different power settings and different electrode positions over the tissue: perpendicular, parallel and with an angle of $45^{\circ}$ (we'll refer to this position as "oblique"). As Figure 2a shows, there were no important differences in the incidence of steam pops between the two electrode designs: for both electrodes the steam pops occurred at powers higher than $35 \mathrm{~W}$ with the electrode in perpendicular position, whereas with the electrode in other positions the steam pops occurred already at $30 \mathrm{~W}$. However, a difference was observed in the occurrence time of the steam pop between electrodes in the oblique position: in the specific, at $30 \mathrm{~W}$ the steam pop occurred 20 s earlier with the multi-holes electrode.

In terms of position in the cardiac tissue, the steam pop was located at approximately $2 \mathrm{~mm}$ of depth beneath the electrode tip for both electrode designs, except for the case of electrode in parallel position (see Figure 2b). In this case and especially with the 6-holes electrode, the steam pop was located in the tissue $\approx 0.5 \mathrm{~mm}$ above the previous position.

\section{Discussion}

We used a computational model of an open-irrigated electrode for endocardial RFCA presented at the past CinC conference [3] with the aim to predict the occurrence and location of steam pops in the tissue under different simulated clinical situations. We assumed that a steam pop occurred for a temperature in the tissue domain higher than $89.3^{\circ} \mathrm{C}$. The feasibility of the model was firstly assessed against previous experimental studies
[2,8] using a 6-holes electrode in perpendicular position with respect to the tissue as in the existing experiments for steam pop occurrence [2]. We obtained similar results to the existing experimental ones [2,8]: 1) the calculated rate of volumetric temperature change was always larger than $1.5^{\circ} \mathrm{C} / \mathrm{s}$ when a steam pop occurred in the tissue, 2) the ablation time, stopped after the pop occurrence, was $\approx 30 \mathrm{~s}$ for a power of $35 \mathrm{~W}$, and 3 ) the maximum temperature at the catheter tip registered with the model reproduced the experimentally measured for each power setting.

In this way, we setup a confident model able to assess the time of pop occurrence and its location in the cardiac tissue. These two parameters are really difficult to estimate in a clinical stage with the current available techniques, in particular the location of the pop inside the tissue. For this reason, we conducted a new set of simulations in which we compared two electrode designs under different power settings and electrode positions over the tissue surface (perpendicular, parallel and oblique). Our results show no steam pops occurrence for powers of $20 \mathrm{~W}$, for both catheters in any position over the tissue surface, in agreement with the experimental results obtained by Guerra et al. [5]. We also observed no significant difference in the incidence of steam pop between the two electrode designs. This is in agreement with a previous experimental report of Nakagawa [9], comparing the incidence of steam pops with the 12- and 56-holes electrode using power settings from 30 to $50 \mathrm{~W}$. Steam pops occurred at power settings higher than $30 \mathrm{~W}$, except for the case of electrode in perpendicular position (no pops occurred up to $35 \mathrm{~W}$ ). These results support the findings of a recent experimental study [8], where steam pops are obtained for powers from $35 \mathrm{~W}$ on, for both 6holes and 56-holes electrode, but where $30 \mathrm{~W}$ was not tested power (only 20,35 and $50 \mathrm{~W}$ ) and where the electrode position on the tissue is not reported.

Regarding the location of the steam pop inside the cardiac tissue, computer results suggest that the pop is located at $\sim 2 \mathrm{~mm}$ depth beneath the electrode tip, except for the case of parallel position. In this case the pop is located closer to the electrode tip. This is probably due to the larger contact surface with the tissue, which enhances the heat transfer between the electrode tip and the tissue, thus shifting the hottest point up towards the contact surface. 
Future studies could be conducted with this model in order to assess the incidence of steam pops under other clinical circumstances that surely have impact in pop formation, by taking into account, for example, different electrode insertion depth into the tissue, different electrode materials, or longer ablation times (in this study the latter was limited to $60 \mathrm{~s}$ ).
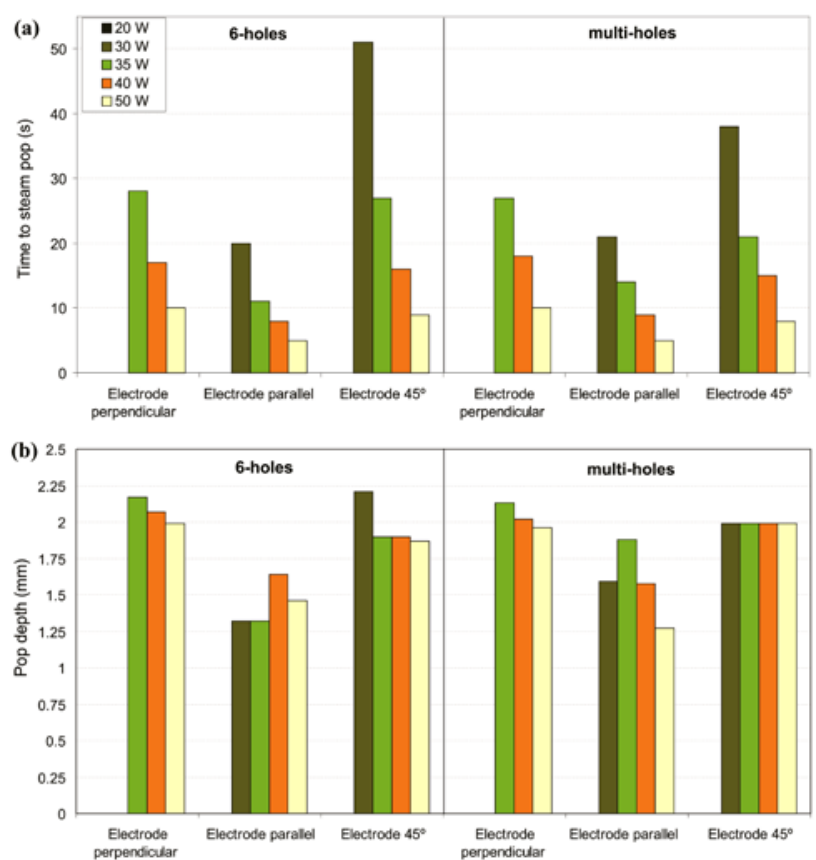

Figure 2. Time to steam pop (a) and depth of the pop in the cardiac tissue (b) for the 6-holes and 56-holes electrode for different electrode position over the tissue and power settings.

\section{Conclusions}

We setup a computational model to predict the occurrence and location of pops during irrigated RFCA. Our results were in close agreement with previous experimental results in terms of pop occurrence and time to pop. In addition, the model was used to compare the performance of two electrode designs in terms of pop occurrence. Our findings show no evidence of significant differences in the incidence of steam pops between the two catheter designs we considered: this aspect will be further investigated.

\section{Acknowledgements}

This work was supported in part by the Basque Government through the BERC 2014-2017 program and by Spanish Ministry of Economy and Competitiveness MINECO through the BCAM Severo Ochoa excellence accreditation SEV-2013-0323, and also by the Spanish "Plan Estatal de Investigación, Desarrollo e Innovación
Orientada a los Retos de la Sociedad" under Grant TEC2014-52383-C3-R (TEC2014-52383-C3-1-R) and Grant MTM2015-69992-R. A. González-Suárez has a Postdoctoral Grant (APOSTD/2016/045) from the Generalitat Valenciana.

\section{References}

[1] Chik WW, Kosobrodov R, Bhaskaran A, Barry MA, Nguyen DT, Pouliopoulos J, Byth K, Sivagangabalan G, Thomas SP, Ross DL, McEwan A, Kovoor P, Thiagalingam A. Acoustic signal emission monitoring as a novel method to predict steam pops during radiofrequency ablation: preliminary observations. J Cardiovasc Electrophysiol. 2015;26(4):440-7.

[2] Koruth JS, Dukkipati S, Gangireddy S, McCarthy J, Spencer D, Weinberg AD, Miller MA, D'Avila A, Reddy VY. Occurrence of steam pops during irrigated RF ablation: novel insights from microwave radiometry. J Cardiovasc Electrophysiol. 2013 Nov;24(11):1271-7.

[3] González-Suárez A, Berjano E, Guerra JM, Gerardo-Giorda L. A Computational Model of Open-irrigated Electrode for Endocardial RF Catheter Ablation. Computing in Cardiology 2015; 42:73-76

[4] González-Suárez A, Berjano E, Guerra JM, Gerardo-Giorda L. Computational Modeling of Open-Irrigated Electrodes for Radiofrequency Cardiac Ablation Including Blood Motion-Saline Flow Interaction. PLoS One. 2016 Mar;11(3):e0150356.

[5] Guerra JM, Jorge E, Raga S, Gálvez-Montón C, AlonsoMartín C, Rodríguez-Font E, Cinca J, Viñolas X. Effects of open-irrigated radiofrequency ablation catheter design on lesion formation and complications: in vitro comparison of 6 different devices. J Cardiovasc Electrophysiol 2013;24(10):1157-62.

[6] Berjano EJ. Theoretical modeling for radiofrequency ablation: state-of-the-art and challenges for the future. Biomed Eng Online 2006;5:24.

[7] González-Suarez A, Berjano E. Comparative Analysis of Different Methods of Modeling the Thermal Effect of Circulating Blood Flow During RF Cardiac Ablation. IEEE Trans Biomed Eng 2015;63(2):250-259.

[8] Winterfield JR, Jensen J, Gilbert T, Marchlinski F, Natale A, Packer D, Reddy V, Mahapatra S, Wilber DJ. Lesion size and safety comparison between the novel flex tip on the flexability ablation catheter and the solid tips on the thermoCool and ThermoCool SF ablation catheters. J Cardiovasc Electrophysiol 2016; 27:102-189.

[9] Nakagawa H. Comparison of 12 and 56 hole electrodes for open irrigated radiofrequency ablation in a canine thigh muscle preparation: improvement in thrombus reduction with 56 small irrigation holes. Biosense Webster 2010.

Address for correspondence.

Ana González-Suárez \{agonzalezs@bcamath.org BCAM-Basque Center for Applied Mathematics Alameda de Mazarredo, 14 E-48009 Bilbao, Basque Country-Spain 